\title{
CRIMES CONTRA A HUMANIDADE: CONJECTURAS DA RESPONSABILIDADE INTERNACIONAL DE NICOLÁS MADURO
}

\author{
Camila Martins de Oliveira ${ }^{1}$ \\ Escola Superior Dom Helder Câmara (ESDHC) \\ Clara de Castro Nassif ${ }^{2}$ \\ Escola Superior Dom Helder Câmara (ESDHC) \\ Matheus Mendonça Ribeiro Nepomuceno ${ }^{3}$ \\ Escola Superior Dom Helder Câmara (ESDHC)
}

\section{Resumo}

A República Bolivariana da Venezuela enfrenta, desde o século XX, ampla deterioração democrática, agravada por uma crise humanitária e altíssimos índices de inflação. Diante deste contexto, o país ainda vivencia uma grave crise política e Nicolás Maduro é o presidente de facto, apesar da questionável legitimidade do processo eleitoral e da forte perda de reconhecimento no cenário internacional. Neste contexto, a pesquisa faz conjecturas acerca da responsabilidade internacional de Nicolás Maduro, frente ao Tribunal Penal Internacional, buscando compreender se atos por ele praticados podem ser considerados crimes contra a humanidade, vedados pelo art. $7^{\circ}$ do Estatuto de Roma de 1998. Desse modo, o trabalho perscruta o contexto histórico que precede o governo Maduro e reflete problemas institucionalizados na Venezuela, explora o Estatuto de Roma e o Tribunal Penal Internacional, por ele instituído, em sua amplitude e limitaçóes, e examina o relatório da Comissáo Interamericana de Direitos Humanos de 2017 sobre a Venezuela. No que tange ao método, a pesquisa utilizará o juízo hipotético-dedutivo, traçando conjecturas sobre a responsabilização

1 Doutoranda em Direito Ambiental e mestre pela Escola Superior Dom Helder Câmara (ESDHC). Pesquisadora do Grupo de Iniciação Científica sobre os julgados do Tribunal Pena Internacional (TPI). Professora de Direito Penal na EESDHC. Professora de Direito Penal Ambiental na Pós-graduação Lato Sensu da PUC-Minas. Advogada. ORCID: https://orcid.org/0000-0003-3115-4056/ e-mail: camartinsoliveira1@gmail.com

2 Graduanda em Direito, modalidade integral, na ESDHC. Estagiária do Centro de Simulação e Intercâmbio. Pesquisadora do Grupo de Iniciação Científica sobre os julgados do TPI. Integrante do Centro de Estudos em Jurisprudência (CEJUR). ORCID: http://orcid.org/0000-0002-4486-3655 / e-mail: nassifdecastroclara@gmail.com 3 Graduando em Direito, modalidade integral, pela ESDHC. Pesquisador do Grupo de Iniciação Científica sobre os julgados do TPI. Integrante do Centro de Estudos em Jurisprudência (CEJUR). ORCID: http://orcid.org/00000002-4698-5760 / e-mail: matheusmendoncarn@gmail.com 
internacional através do Tribunal Penal Internacional. Por fim, os embates aqui analisados constatam que crimes contra a humanidade foram cometidos durante os governos de Maduro e tem-se, portanto, violaçáo de jus cogens passível de julgamento pelo TPI, uma vez verificada a competência da competência.

Palavras-chave: crimes contra a humanidade; Tribunal Penal Internacional; Venezuela.

\section{CRIMES AGAINST HUMANITY: CONJECTURES FOR THE INTERNATIONAL RESPONSIBILITY OF NICOLÁS MADURO}

\section{Abstract}

The Bolivarian Republic of Venezuela has been facing, since the XX century, a wide democratic deterioration, aggravated by a humanitarian crisis and high rates of inflation. In view of this, the country still faces a deep political crisis and has Nicolás Maduro as official president, even with questionable electoral legitimacy process and a strong loss of recognition in the international scene. Within this context, this research does conjectures regarding Nicolás Maduro's international responsibility, before the International Criminal Court, aiming to understand if acts performed by him can be considered crimes against humanity, sealed by the 7th Article of the Rome Statute of 1998. Therefore, the research examines the historical context that preceded Maduro's government and reflects institutionalized problems in Venezuela, exploits the Rome Statute and the International Criminal Court, instituted by him in his amplitude and limitations, and examines the Inter-American Commision on Human Rights report of 2017 regarding Venezuela. Regarding the methods used, the proposed research will use hypothetic-deduction, making conjectures regarding the international accountability through the International Criminal Court. Last$l y$, the conflicts here analyzed will demonstrate what crimes against humanity were practiced during Maduro's government and the violation of jus cogens justiciable by the ICC, once jurisdiction has been established.

Keywords: crimes against humanity; International Criminal Court; Venezuela. 


\section{Introdução}

A República Bolivariana da Venezuela enfrenta, desde o século XX, ampla deterioração democrática, com baixa alternância de governos e consequente manutenção de políticas, contexto agravado por uma crise humanitária e altíssimos índices de inflação. Diante deste contexto, o país ainda vivencia uma grave crise política e Nicolás Maduro é o presidente de facto, apesar da questionável legitimidade no processo eleitoral e da forte perda de reconhecimento do presidente no cenário internacional.

De posse desde 2013, Maduro tem atuado de maneira atentatória aos direitos humanos, em especial após o Decreto n. 2849 de 2016, ${ }^{4}$ que estabeleceu um novo estado de exceção e emergência em todo o território da Venezuela, outorgando amplos poderes discricionários ao Executivo para derrogar direitos humanos através de medidas especiais. Por certo, as medidas adotadas pelo efetivo poder venezuelano repercutem duras críticas internacionais, o que desencadeou duas denúncias contra Maduro ao Tribunal Penal Internacional (TPI), sendo a última, pela primeira vez, submetida por um grupo de Estados Partes.

A Venezuela ratificou o Estatuto de Roma em 7 de junho de 2000. Portanto, o TPI pode exercer sua jurisdiçấo sobre os crimes do referido estatuto cometidos no território da Venezuela ou por seus nacionais a partir de $1^{\circ}$ de julho de 2002, data de criação do Tribunal. Segundo o próprio Tribunal (ICC, 2018), a última denúncia contra Maduro, e mais ampla, solicita à Promotoria do TPI que se inicie uma investigação sobre crimes contra a humanidade supostamente cometidos no território da Venezuela desde 12 de fevereiro de 2014. Factualmente, o mundo acompanha a crise que se desenvolve no país à espera de respostas efetivas, em especial, por parte de organismos internacionais.

Desse modo, a amplitude da denúncia somada aos escassos detalhes divulgados pelo tribunal, na contramão das esperadas soluçóes, deixa a comunidade internacional a esmo dos crimes supostamente cometidos, sem uma perspectiva palpável de quais seriam as práticas adotadas por Nicolás Maduro que de fato poderiam ser classificadas como crimes de lesa humanidade. Sendo assim, é de intento desta pesquisa averiguar sucintamente quais medidas tomadas por Maduro podem ser apontadas como crimes contra a humanidade e qual consequente possibilidade de julgamento de Maduro pelo TPI.

\footnotetext{
4 Decreto n. 2.849, segundo o qual o Estado de Exceção e Emergência Econômica é declarado em todo o território nacional, dadas as circunstâncias extraordinárias nas esferas social, econômica e política que afetam a ordem constitucional, a paz social, a segurança da Naçáo, as instituiçóes públicas e os cidadãos da República, para que o Executivo Nacional adote as medidas urgentes, vigorosas, excepcionais e necessárias para assegurar à população o pleno gozo de seus direitos, preservar a ordem, acesso interno e oportuno a bens, serviços, alimentos, medicamentos e outros produtos essenciais para a vida (SANTANA, 2018, p. 187, livre tradução do autor).
} 
A pesquisa que se propóe utilizará do juízo hipotético-dedutivo, traçando conjecturas sobre a responsabilização internacional através do Tribunal Penal Internacional. Será analisada a possibilidade de condenação de Nicolás Maduro pelo Tribunal Penal Internacional por meio dos documentos disponibilizados pelo Tribunal, pela Organização do Estados Americanos, além dos órgãos filiados à Organização das Naçôes Unidas, visando identificar se os delitos suprem as determinaçôes internacionais para serem julgados por um órgão supranacional.

\section{Contexto histórico}

O espectro social venezuelano em estudo vem sendo construído ao longo dos anos e, portanto, não se trata de uma atribuiçáo exclusiva do governo de Nicolás Maduro ou mesmo de Hugo Chávez, seu antecessor. Por certo, desde o descobrimento de grandes jazidas de petróleo na Venezuela, no início do século $\mathrm{XX}$, nota-se o tradicionalismo institucional venezuelano para a propagação da economia concentrada no petróleo. Vem sendo instaurado, então, o rentismo econômico.

Nas palavras de Jorge Giordani (2005 apud BARROS, 2006, p. 2) "a Venezuela continua vivendo da dita renda petroleira, que não se produz, mas sim se capta" e, de acordo com o relatório:

“[...] Hacia Una Venezuela Productiva”, de 2004, do Ministério do Desenvolvimento e Planejamento da Venezuela "a Venezuela continua sendo um país rentista, cuja riqueza majoritariamente vem captada do exterior mediante a apropriação de um excedente que permitiu, com a exportação petroleira, manter um saldo comercial e de serviços positivos para o país (MPD, 2004 apud BARROS, 2006, p. 2).

Ao longo dos anos, desde o século XX, as exportaçôes de petróleo cresceram acentuadamente, chegando ao ponto de dependência fática da matriz energética. ${ }^{5}$

Tabela 1 Exportações venezuelanas, 1920 - 1945 (milhôes em bolívares)

\begin{tabular}{|c|c|c|c|c|c|c|c|}
\hline Ano & Totais & Petrolíferas & $\mathbf{\%}$ & Cacau e café & $\mathbf{\%}$ & Outros & $\mathbf{\%}$ \\
\hline 1920 & 173,3 & 3,1 & 1,7 & 100,7 & 58,1 & 69,5 & 40,2 \\
\hline 1925 & 373,1 & 173,9 & 44,6 & 155,2 & 41,6 & 44 & 11,8 \\
\hline 1930 & 986,1 & 838,4 & 85,1 & 85,2 & 8,6 & 62,5 & 6,3 \\
\hline 1935 & 528,9 & 455,3 & 86,1 & 37,7 & 7,1 & 35,9 & 6,8 \\
\hline 1940 & 531,3 & 467,0 & 87,9 & 25,2 & 4,7 & 39,1 & 7,4 \\
\hline 1945 & 1241,5 & 1126,9 & 90,8 & 47,8 & 3,8 & 66,8 & 5,4 \\
\hline
\end{tabular}

Fonte: Baptista (1991, p. 96).

5 No decorrer deste artigo serâo utilizadas diversas informaçóes jornalísticas, por serem as únicas disponíveis até o momento, para sustentar e ilustrar a temática escolhida, sem que com isso seja deixada de lado a cientificidade que é necessária à pesquisa jurídico-científica. 
Como mostra a tabela supra, o petróleo já correspondeu a 90,8\% de toda a exportação venezuelana e, ainda hoje, a exportação do petróleo responde por quase toda a receita de exportaçáo e quase metade das receitas do governo (CIA, 2020). Membro fundador da Organização de Países Exportadores de Petróleo (OPEP), a Venezuela optou pelo desenvolvimento por meio do endividamento externo, com ampla cessão de crédito a um preço animador, dadas as garantias exequíveis pela abundância de petróleo (HITNER, 2011). No entanto, com tamanha dependência de tal recurso, sem uma larga diversificaçáo da matriz econômica, os câmbios petrolíferos em suas significativas baixas e altas refletem substancialmente na economia venezuelana.

Segundo a Comissão Econômica para a América Latina e Caribe (CEPAL), em análise disponibilizada no Balanço Preliminar das Economias da América Latina e Caribe de 2019, a dívida externa bruta da Venezuela em 2018 foi de U\$ 151, 20 bilhóes. Além disso, segundo o mesmo balanço o produto interno bruto do país caiu $25,5 \%$ em 2019, e um dos motivos apresentados para essa redução foi a diminuição na venda do petróleo, que reduziu em $36 \%$ quando comparado a índices de 2018, como é possível perceber no trecho a seguir:

El PIB de la economía venezolana se redujo un $25,5 \%$ en 2019 , lo que supone una contracción acumulada del 62,2\% respecto del nivel de 2013. Durante 2019 se mantuvo el proceso hiperinflacionario que se inició en noviembre de 2017, y a septiembre de 2019 la tasa de inflación anualizada fue del 39.113\%. En 2019 también se agudizó la restricción externa que enfrenta la economía venezolana, dadas las menores exportaciones petroleras (descenso del 36\% con respecto a 2018) y el limitado acceso a mercados financieros internacionales. Se estima que en 2019 se registrará un superávit en la balanza comercial del 12,7\% del PIB, lo que significa una reducción respecto al superávit observado en 2018 (un 17,6\% del PIB). Asimismo, por quinto año consecutivo se prevé una caída en las reservas internacionales. Las autoridades venezolanas continuaron el proceso de desmontaje del control de cambio y se pasó a un sistema de mayor flexibilidad, lo que, hasta noviembre de 2019, significó una depreciación mayor que el $4.900 \%$ del tipo de cambio oficial. Para 2020, dada la severa restricción externa que enfrenta el país, la prolongación de la caida en la actividad petrolera, la menor disponibilidad de combustible en el mercado interno y la poca recuperación del sector eléctrico venezolano, se espera un nuevo descenso del PIB (14,0\%) y una inflación que, aunque se está reduciendo, se mantendrá en niveles históricamente altos (CEPAL, 2020). ${ }^{6}$

6 O PIB da economia venezuelana caiu $25,5 \%$ em 2019, o que representa uma contração acumulada de $62,2 \%$ em relação ao nível de 2013. Durante 2019, permaneceu o processo hiperinflacionário iniciado em novembro de 2017 
Vale salientar, ainda, conforme expóe Verena Hitner (2012), que "uma vez que o dinamismo econômico é ditado pela apropriação de uma renda internacional, a disputa entre as classes sociais pela participação no excedente é uma disputa pelo poder político". Assim, economicamente, temos uma Venezuela extremamente desigual dada a alta concentração de renda em um único commodity, o que favorece classes específicas da sociedade, estando o Estado fortemente endividado, e sendo a população socialmente mais frágil a que sofre diretamente as consequências de tal mazela.

Não obstante, apesar de o fator econômico ter grande importância para o estudo da Venezuela atual, é necessário compreender, também, o aspecto político, que está arraigado aos aspectos econômicos descritos, e que antecedem ao governo Maduro, ao qual se destinam as conjecturas desta pesquisa. Factualmente, a história da Venezuela é marcada por instabilidades, tanto em governos autoritários quanto democráticos, e em 1958, na busca por tal governabilidade, consolida-se o Pacto de Punto Fijo, constituído com base material clientelista da renda petrolífera (VILLA, 2005).

Segundo Pedro Silva Barros, o Pacto de Punto Fijo foi um acordo de governabilidade diante do qual o governo, em parceria com as forças armadas, comprometeu-se a defender a democracia representativa. Na prática, foi um período de alternância de poder, mas sem uma alteração de políticas públicas, forjado pelos partidos Comité de Organización Política Electoral Independiente (COPEI) e Acción Democrática (AD), após a queda da ditadura de Marcos Pérez Jiménez, que vigorou por quarenta anos, até a eleição de Hugo Chávez em 1998 - o período também é conhecido na bibliografia venezuelana como democracia formal - (BARROS, 2006).

O desgaste da política puntufijista, em grande parte dado pela crise latino-americana ao final da década de 70 , adstrito à crise política, que por sua vez está arraigada pela instabilidade de governança, possibilitou a ascensão de Hugo Chávez ao poder (Hitner, 2012). O candidato com discurso de grandes rupturas no status quo tornou-se aquele que melhor interpretava o clamor popular por mudanças e, uma vez eleito em 1998, convocou uma Assembleia Nacional Constituinte e promulgou a atual Constituição da República Bolivariana da Venezuela (1999).

O governo de Hugo Chávez propôs justamente uma refundação do Estado

e em setembro de 2019, a taxa de inflaçáo anualizada foi de 39.113\%. Em 2019, acirrou-se a restrição externa à economia venezuelana, dadas as menores exportaçóes de petróleo (redução de 36\% em relação a 2018) e acesso limitado aos mercados financeiros internacionais. Estima-se que um superávit seja registrado em 2019 na balança comercial de $12,7 \%$ do PIB, o que significa uma redução em relação ao superávit observado em 2018 (17,6\% do PIB). Além disso, pelo quinto ano prevê-se consecutiva queda nas reservas internacionais. As autoridades venezuelanas continuaram o processo de desmantelar o controle cambial e passaram a um sistema mais flexível que, até novembro de 2019, significava uma depreciaçăo superior a $4.900 \%$ da taxa de câmbio oficial. Para 2020, dada a severa restriçấo externa enfrentada pelo país, o prolongamento da queda da atividade petrolífera, a menor disponibilidade de combustível no mercado interno e a baixa recuperaçáo do setor elétrico venezuelano, espera-se um novo declínio do PIB (14,0\%) e inflaçáo que, apesar de reduzida, permanecerá em níveis historicamente altos (livre tradução do autor). 
venezuelano, por meio da elaboração desta nova constituição com ampla proteção aos direitos humanos e, com eloquência nacionalista e bolivariana, pretendeu transformar radicalmente a estrutura econômica, mas acabou sendo limitado pela pujança do legado institucional do país construído sobre a dependência do petróleo e a lógica rentista (LOPES, 2011).

Chávez decerto trouxe grandes avanços às diversas camadas sociais do país, mas após um breve golpe de estado em 2002, ele e seus seguidores agiram com o objetivo de concentrar o poder, assumiram o controle do Supremo Tribunal e diminuíram a capacidade de jornalistas, defensores de direitos humanos e outros venezuelanos de exercerem direitos fundamentais, trazendo censura às críticas ao governo (VENEZUELA..., 2013).

Hugo Chávez conseguiu se manter na chefia do Poder Executivo Venezuelano por quatorze anos, sendo reeleito três vezes, entretanto náo chegou a ser empossado no último período devido a complicaçóes médicas. $\mathrm{O}$ vice-presidente da chapa que Chávez concorria em 2012, era Nicolás Maduro, que assumiu o poder de maneira interina até que as eleiçôes fossem convocadas novamente, situação que culminou em sua eleição de facto, de maneira integral (OHCHR, 2019).

Em 2018, Maduro foi reeleito, entretanto, o pleito realizado tornou-se controverso, com suspeitas de fraude eleitoral, não foi reconhecido pela oposição e por grande parte da sociedade internacional. O presidente da Assembleia Nacional Juan Guaidó é atualmente reconhecido por mais de 50 países como presidente interino, não obstante, o controle efetivo do país ainda está com Nicolás Maduro, uma vez que comanda as Forças de Seguranças da Venezuela e todas as outras instituiçôes, exceto a Assembleia Nacional (CIA, 2020).

\section{Tribunal Penal Internacional}

Relevante parte deste trabalho consiste em perscrutar, não somente o atual contexto venezuelano de desrespeito aos Direitos Humanos, mas também em examinar como o Tribunal Penal Internacional pode ser efetivo em sustar essas violaçóes cometidas na figura do Ditador Nicolás Maduro.

Para tanto, cabe a análise das temáticas que envolveram a criação desse órgão internacional, seu funcionamento e sua regulamentação.

Historicamente o TPI foi instaurado em virtude da hecatombe das grandes Guerras Mundiais, que assolaram e imprimiram marcas profundas na humanidade, pois surgiu a necessidade de responsabilizar os indivíduos que cometeram as inúmeras barbáries presentes nesses conflitos mundiais.

Os tribunais ad hoc de Nuremberg e de Tóquio foram a resposta da sociedade 
internacional a tamanha atrocidade, haja vista que o desenvolvimento desse mecanismo jurídico é um componente muito importante no contexto pós-conflito, já que promove, além da sanção, o debate sobre a necessidade de trabalhar em favor da paz e da reconciliação do meio internacional, diante dos pedidos de justiça das vítimas de violaçóes de direitos humanos.

O tribunal ad hoc de Nuremberg foi estabelecido em 8 de agosto de 1945, formado pelos quatro países vencedores da segunda Grande Guerra, sendo eles Estados Unidos, União Soviética, França e Inglaterra. Não se pretende questionar o caráter político deste tribunal (GONÇALVES, 2009), não obstante é fundamental ressaltar a importância da Carta de Nuremberg, tratado internacional que instaurou esse órgáo. Isso, pois, tal documento sistematizou os julgamentos feitos, evidenciando as falhas, para que não fossem repetidas (FERNANDES, 2013).

O tribunal ad hoc de Tóquio, também chamado de Tribunal Militar Internacional para o Extremo Oriente, foi instituído na Conferência do Cairo em 1994, e firmou objetivo de interromper as agressôes japonesas cometidas durante a Segunda Guerra Mundial e julgar os nacionais que eram considerados criminosos de guerra (SILVA, 2013). Tal órgão foi essencial para a constituição do que se conhece atualmente como TPI, uma vez que ratificou aquilo já disposto no Estatuto de Nuremberg.

No século XIX, apenas os crimes de guerra eram puníveis. Após a Segunda Guerra Mundial, novas categorias de crimes foram desenvolvidas, os tribunais ad hoc de Nuremberg e Tóquio inauguraram os crimes contra a humanidade e contra a paz, seguidos em 1948 pelo genocídio, como subcategoria de crimes contra a humanidade que, posteriormente, torna-se uma categoria autônoma. Todos esses crimes foram elencados no Estatuto de Roma (BRASIL, 2002) e, durante a conferência de revisão, em 2010, fora tipificado o crime de agressão.

O Estatuto de Roma (BRASIL, 2002), em seu art. $1^{\circ}$, estabelece a criaçáo do Tribunal Penal Internacional (TPI) que, no entanto, só se constituiu em 2002, momento em que se alcança o número mínimo de Estados Partes que ratificam tal documento.

O TPI efetiva a sanção para os crimes internacionais mais graves, segundo a subsidiariedade, como o genocídio, os crimes de guerra, os crimes de agressão e os crimes contra a humanidade. Composto por 18 juízes - sendo um presidente, um primeiro e um segundo vice -, pela Assembleia dos Estados Partes, por órgãos de supervisão administrativa e legislativa do TPI, além do gabinete da promotoria (ESTATUTO DE ROMA, 2019).

O Direito Internacional Penal surge à medida que a sociedade internacional define as condutas pelas quais o autor é considerado criminalmente responsável. 
Este é um corpo de regras destinado tanto a coibir os crimes internacionais, quanto a impor aos Estados a obrigaçáo de processar e punir tais crimes, além de regular os procedimentos internacionais para processar e julgar as pessoas acusadas (CASSESE apud JANKOV, 2009). Suas fontes passíveis de aplicaçáa pelo TPI são, em primeiro lugar, o Estatuto de Roma, os elementos constitutivos do crime e o regulamento processual; em segundo, se for o caso, os tratados, os princípios e as normas de Direito Internacional, a lembrar o art. $38, \$ 1^{\circ}$ do Estatuto da Corte Internacional de Justiça:

\begin{abstract}
A Corte, cuja função é decidir de acordo com o direito internacional as controvérsias que lhe forem submetidas, aplicará: a. as convençôes internacionais, quer gerais, quer especiais, que estabeleçam regras expressamente reconhecidas pelos Estados litigantes; b. o costume internacional, como prova de uma prática geral aceita como sendo o direito; c. os princípios gerais de direito, reconhecidos pelas naçóes civilizadas; d. sob ressalva da disposiçâo do artigo 59, as decisóes judiciárias e a doutrina dos juristas mais qualificados das diferentes naçôes, como meio auxiliar para a determinação das regras de direito (ESTATUTO DA CORTE INTERNACIONAL DE JUSTIÇA, 1945).
\end{abstract}

$\mathrm{Na}$ falta destes, aplicar-se-ão os Princípios Gerais do Direito Internacional Penal, que são aqueles derivados do direito penal interno. Assim, o Tribunal Penal Internacional se valerá dessas fontes para processar e julgar as quatro categorias de crimes internacionais previstas no Estatuto de Roma, quando cometidos.

Um dos princípios que rege o Tribunal Penal Internacional é o da complementaridade, presente no art. $1^{\circ}$ do Estatuto de Roma, esse princípio aduz que esse órgão só deverá julgar os casos em que o sistema judiciário nacional demonstrar-se incapaz ou indisposto a julgar (CASSESE, 2005, p. 12).

Diante de todo o exposto, é possível a apreciaçáo do contexto venezuelano diante das consideraçóes tecidas acerca do Estatuto de Roma, bem como do Tribunal Penal Internacional.

\title{
3 A Venezuela e o Estatuto de Roma
}

Assim como as demais cortes internacionais, sabe-se que o Tribunal Penal Internacional reúne limitaçóes de competência em virtude de determinados fatores.

Nota-se, pois, que o Tribunal possui competência ratione temporis, que limita a jurisdição da corte aos crimes cometidos após a entrada em vigor do Estatuto; 
Estatuto, art. $11, \$ 1^{\circ}$, aos países que aderiram ao Estatuto após sua vigência a jurisdiçáo é prestada somente após o vigor deste para o Estado em questão (ratificação); art. $11, \mathbb{\$} 2^{\circ}$, competência ratione loci, que em princípio geral limita a jurisdição do tribunal aos crimes cometidos no território dos Estados-Membros, independentemente da nacionalidade do acusado; conforme o art. $12, \$ 2^{\circ}$, competência ratione personae que incide sobre pessoas naturais (excluindo, portanto, Estados e Organizaçóes Internacionais de sua jurisdição); art. 1 e $25, \$ 1^{\circ}$, e jurisdiçáo ratione materiae, cuja competência recai sobre quatro tipos de crime: genocídio, crimes contra a humanidade, crimes de guerra e agressão.

Neste contexto, no tocante à jurisdição ratione materiae a pesquisa desenvolverá apenas o conceito de crimes contra a humanidade para análise de sua imputação, adstrito às demais competências supracitadas. Ademais, é de extrema importância a adequação do fato analisado às competências do tribunal, visto que qualquer fator que ultrapasse os limites expressos não será passível de análise jurisdicional.

As açóes que serâo analisadas posteriormente, averiguando a possibilidade de adequação a crimes contra a humanidade, convergem-se inicialmente a Nicolás Maduro (competência ratione personae), ocorreram no território Venezuelano (competência ratione loci), entre os anos de 2014 e 2018, sendo que é manifesta a ratificaçáo do Estatuto de Roma pela Venezuela no ano 2000 (competência ratione temporis). Desse modo, a chamada competência da competência ${ }^{7}$ é procedente e, portanto, o Tribunal Penal Internacional pode julgar tais feitos se estes reputarem à jurisdição ratione materiae.

Nesse diapasão, é imperioso compreender quais são os crimes contra a humanidade e os limites de seu conceito, tratando-se de matéria penal em âmbito internacional. O Estatuto de Roma, art. $7^{\circ}, \$ 1^{\circ}$, afirma:

Para os efeitos do presente Estatuto, entende-se por "crime contra a humanidade", qualquer um dos atos seguintes, quando cometido no quadro de um ataque, generalizado ou sistemático, contra qualquer população civil, havendo conhecimento desse ataque: a) Homicídio; b) Extermínio; c) Escravidão; d) Deportação ou transferência forçada de uma população; e) Prisão ou outra forma de privaçâo da liberdade física grave, em violação das normas fundamentais de direito internacional; f) Tortura; g) Agressão sexual, escravatura sexual, prostituição forçada, gravidez forçada, esterilizaçáo forçada ou qualquer outra forma de violência no campo sexual de gravidade comparável; h) Perseguição de um grupo ou

7 Competência da competência trata-se de decorrência inevitável do magistrado da causa, no caso o tribunal, poder verificar a satisfaçăo dos pressupostos processuais. Se a competência é um desses pressupostos, é natural que se tenha, também, o poder de decidir (ao menos em primeira análise) sobre sua competência (GOMEZ, 2011). 
coletividade que possa ser identificado, por motivos políticos, raciais, nacionais, étnicos, culturais, religiosos ou de gênero, tal como definido no parágrafo $3^{\circ}$, ou em função de outros critérios universalmente reconhecidos como inaceitáveis no direito internacional, relacionados com qualquer ato referido neste parágrafo ou com qualquer crime da competência do Tribunal; i) Desaparecimento forçado de pessoas; j) Crime de apartheid; $\mathrm{k}$ ) Outros atos desumanos de caráter semelhante, que causem intencionalmente grande sofrimento, ou afetem gravemente a integridade física ou a saúde física ou mental (BRASIL, 2002).

Tem-se, então, um rol dos crimes de lesa humanidade, que almeja se aproximar do princípio da taxatividade, na medida em que o parágrafo segundo deste mesmo artigo realiza uma interpretação intra legem do que se entende por estes crimes. Destaca-se, ainda, o fato de os crimes contra a humanidade representarem cerca de 60\% das acusaçốes constantes nos 27 casos já públicos pelo tribunal (ICC, 2018), o que denota a importância dada ao cumprimento desta norma.

Posto isto, é necessário voltar as atençóes ao governo Maduro, retrocedendo a 2013, ano em que o Congresso da Venezuela aprova uma lei que autoriza o presidente a governar por decretos (PRIMERA, 2013). Já nos primeiros anos de governo, Maduro, buscando consolidar sua governabilidade, com apoio dos tribunais nacionais, ampliou o conteúdo e alcance das restriçôes de manifestaçôes populares, tornando-as incompatíveis com os parâmetros internacionais sobre a matéria, agravando tais restriçôes a ponto de, em 2014, decretar a proibição de manifestaçóes públicas de cunho político (CIDH, 2017).

Sem receio de utilizar todo o aparato estatal a seu controle, Maduro, conforme o relatório da Comissão Interamericana de Direito Humanos (2017), institucionaliza violaçóes massivas de direitos humanos em todo o país. Com tamanha dificuldade para se aferir dados não manipulados sobre o país, o extenso relatório da Comissão se tornou a principal fonte da real situação venezuelana atualmente. Nele consta que, entre abril e agosto de 2017, quatro mil pessoas foram agredidas enquanto se manifestavam, vítimas do uso excessivo da força por parte de militares, o que ocasionou 123 mortes, sendo 15 delas de crianças (CIDH, 2017).

Não obstante, entre 1 de janeiro de 2014 e 31 de outubro de 2017, 11.993 pessoas foram detidas arbitrariamente, sendo que, destas, 5.341 foram detidas durante o período de protestos supracitado (CIDH, 2017). Tem-se o caráter arbitrário confirmado dadas as apuraçôes da Comissão (2017) que revelam que 
$90 \%$ das quase 12.000 prisôes teriam sido realizadas sem ordem judicial e, mesmo após as detenções, foram realizadas denúncias de incomunicações e transferências arbitrárias durante a madrugada, sem nenhuma notificação prévia. As prisôes forçadas constam-se vedadas na Carta de Direito Humanos, a se destacar o Pacto de Direito Civis e Políticos (1966), e constituem crime contra a humanidade, conforme o art. $7^{\circ}, \$ 1^{\circ}, e$, do Estatuto de Roma (BRASIL, 2002), sendo passível, portanto, de julgamento pelo TPI.

Ademais, em 2016 foram identificadas 473 vítimas de tratamentos ou penas cruéis, desumanas ou degradantes; já em 2017 - entre abril e julho - 3.880 pessoas foram detidas e, pelo menos $15 \%$ destas, foram submetidas a tortura ou tratamentos desumanos $(\mathrm{CIDH}, 2017)$. O relatório ainda informa que as práticas de tortura incluíam golpes com paus, armas e barras metálicas, descargas elétricas, sufocamento com substâncias químicas e privação de água e alimentos. Além da tortura, há 25 denúncias pela Asociación Venezolana para Una Educación Sexual Alternativa (AVESA, 2017) de casos de violência sexual, incluindo toques inapropriados e estupros, todos cometidos por agentes do Estado. Tanto a tortura, quanto a violência sexual em quadros de ataques como esses, são crimes contra a humanidade, em consonância com o Estatuto de Roma (BRASIL, 2002), art. 7º, $\S 1^{\circ}, f, g$, respectivamente, e também com o art. $7^{\circ}, \S 2^{\circ}, e$, que taxativamente afirma:

Por "tortura" entende-se o ato por meio do qual uma dor ou sofrimentos agudos, físicos ou mentais, são intencionalmente causados a uma pessoa que esteja sob a custódia ou o controle do acusado; este termo não compreende a dor ou os sofrimentos resultantes unicamente de sanções legais, inerentes a essas sançôes ou por elas ocasionadas (BRASIL, 2002).

Vale salientar, ainda, que tais atos vão de encontro, também, a tratados interamericanos de direitos humanos de que a Venezuela é Estado Parte, tal como a Convenção Interamericana para Prevenir e Sancionar a Tortura (1985) e a Convenção Interamericana para Prevenir, Punir e Erradicar a Violência contra a Mulher ou Convenção de Belém Do Pará (1994).

A Comissão Interamericana de Direitos Humanos solicitou com urgência que o Estado venezuelano se abstenha de praticar detençóes coletivas indiscriminadamente, cumprindo com todos os requisitos impostos pelas leis internas e os parâmetros internacionais sobre detençóes efetuadas pelas forças de segurança em contextos de protestos sociais; condena qualquer ato de tortura ou tratamento cruel, desumano e degradante, e reafirma o caráter cogente desta proibiçáo, sendo corolário do dever do Estado tratar de toda pessoa privada de 
sua liberdade humanamente e com respeito a sua dignidade; e ratifica o dever do Estado de agir com a devida diligência para prevenir e erradicar as formas de violência e discriminação contra as mulheres, além de levar em consideração que os riscos de ser vítimas de violência física, sexual e psicológica são agravados quando se encontram privadas de liberdade e sob o controle das autoridades do Estado (CIDH, 2017).

Com os protestos de 2017 e a violência estatal Venezuelana, a República da Argentina, o Canadá, a República da Colômbia, a República do Chile, a República do Paraguai e a República do Peru, juntos, solicitaram em setembro de 2018, à promotoria do TPI que se inicie uma investigação sobre crimes contra a humanidade em face de um ou mais agentes; o processo se encontra na fase de Pre-Trial Chamber I (ICC, 2018).

O principal documento baseado para encaminhar tal solicitação foi o Report Of The General Secretariat Of The Organization Of American States And The Panel OfIndependent International Experts On The Possible Commission OfCrimes Against Humanity In Venezuela, no qual são detalhados de maneira pormenorizada todos os crimes contra a humanidade que estâo ocorrendo na República Bolivariana da Venezuela.

Como conclusão, o documento trouxe a necessidade de se enviar o relatório ao procurador do Tribunal Penal Internacional e que fosse aberta uma investigação nos moldes do art. 14 de Estatuto de Roma (OEA, 2018). O pedido de investigação foi efetivamente enviado, como descrito supra, e de acordo com notícia divulgada pelo próprio Tribunal a procuradora Fatou Bensouda iniciou o exame preliminar, como é demonstrado no seguinte trecho:

On 8 February 2018, following a careful, independent and impartial review of a number of communications and reports documenting alleged crimes potentially falling within the jurisdiction of the ICC, I decided to open a preliminary examination of the situation in Venezuela to analyse crimes allegedly committed in this State Party since at least April 2017, in the context of demonstrations and related political unrest. Since then, my Office has been assessing the information available in order to reach a fully-informed determination of whether there is a reasonable basis to proceed with an investigation. This preliminary examination will continue to follow its normal course, strictly guided by the requirements of the Rome Statute (ICC, 2018). ${ }^{8}$

A pesquisa denota a existência de tais violação abordadas e, inicialmente,

8 Em 8 de fevereiro de 2018, após uma análise cuidadosa, independente e imparcial de várias comunicaçōes e relatórios que documentam supostos crimes potencialmente sob a jurisdiçấo do TPI, decidi abrir um exame preliminar da 
atribui a Maduro tal imputação, sem, no entanto, excluir a possibilidade responsabilização de outros agentes como militares e funcionários públicos, ou agentes privados que atuem como se Estado fossem. O documento feito pela OEA caminha-se no mesmo sentido, ao afirmar que a fase de investigação deve ater-se a comprovar a existência de atos que descumpram o Tratado de Roma e que a imputaçấo de acusados deve ser posterior; a passagem abaixo comprova tal posicionamento:

At this stage of the procedure in the process of the Office of the Prosecutor it is not necessary to determine personal responsibility, but rather the existence of a reasonable basis that crimes against humanity under the jurisdiction of the ICC have been committed. Without prejudice to this, the Panel, in the preparation of this report, refers to numerous persons, both civilian and military, who, while representing the Venezuela State, participated in the commission of the alleged crimes against humanity, who could eventually be held criminally responsible by the ICC. The Panel notes that the General Secretariat has presented of list of individuals they have identified as allegedly culpable for the crimes presented (OEA, 2018). ${ }^{9}$

Apesar disso, Maduro, por ser o líder regente da Venezuela e comandar a Guarda Nacional que realizou as prisôes arbitrárias citadas, tem a priori responsabilidade por tais atos, mesmo que não tenha praticado a ação delituosa em si, nem as tenha ordenado diretamente.

O Superior Hierárquico é responsável por seus subordinados, segundo três hipóteses detalhadas no art. 28 do Estatuto de Roma: (i) quando o superior sabia, ou conscientemente desconsiderava as informaçóes que indicavam claramente, que os subordinados estavam cometendo ou prestes a cometer tais crimes; (ii) quando os crimes diziam respeito a atividades que estavam sob a responsabilidade e controle efetivo do superior; ou (iii) quando o superior falhou em tomar todas as medidas necessárias e razoáveis ao seu alcance para impedir ou reprimir a realização dos crimes ou não submeteu o assunto às autoridades competentes para investigação e processo (BRASIL, 2002).

situaçáo na Venezuela para analisar crimes supostamente cometidos em este Estado Parte desde pelo menos abril de 2017, no contexto de manifestaçôes e distúrbios políticos relacionados. Desde então, meu Escritório tem avaliado as informaçóes disponíveis para obter uma determinaçấo totalmente embasada de que existe uma base razoável para prosseguir com uma investigação. Este exame preliminar continuará a seguir seu curso normal, estritamente orientado pelos requisitos do Estatuto de Roma (livre traduçáo do autor).

9 Nesta fase do procedimento, não é necessário determinar a responsabilidade pessoal, mas a existência de uma base razoável de que foram cometidos crimes contra a humanidade sob a jurisdição do TPI. Sem prejuízo disso, o Painel, na preparaçẫo deste relatório, refere-se a numerosas pessoas, civis e militares, que, enquanto representando o Estado da Venezuela, participaram da prática dos supostos crimes contra a humanidade, que poderiam eventualmente ser contidos pelo TPI. O Painel observa que a Secretaria Geral apresentou uma lista de indivíduos que identificaram como supostamente culpados pelos crimes apresentados (livre tradução do autor). 
No exame dos documentos apresentados e analisados durante a pesquisa pode-se inferir que os crimes praticados pela Guarda Nacional estavam sob competência e controle de Maduro, o que o enquadraria na segunda hipótese de responsabilização supra, não obstante não se pode descartar a possibilidade de que Maduro claramente sabia das práticas delituosas e com elas compactuava, como na primeira hipótese de responsabilização citada no parágrafo antecedente.

O princípio da complementaridade, uma das bases do TPI, não estaria sendo ferido caso esses delitos fossem julgados, tendo em vista que, a justiça venezuelana não demonstra interesse em julgar os delitos, e mesmo que demonstrasse, o julgamento não seria eficaz, tendo em vista que a influência e poder de Maduro não possibilitariam um julgamento imparcial.

Em consonância com o posicionamento da Comissão, quanto ao caráter cogente das normas que pró́bem a tortura ou tratamento cruel, desumano e degradante, a Corte Interamericana de Direitos Humanos no caso Vladimir Herzog vs. Brasil afirma que "esta proibição de cometer crimes de lesa humanidade é uma norma de jus cogens ${ }^{10}$ e a penalização destes crimes é obrigatória conforme o Direito Internacional geral” (CIDH, 2017), afirmando, ainda, a imprescritibilidade desses crimes.

\section{Conclusão}

Diante do exposto, verifica-se a importância de se efetivar o respeito às instituiçôes, aos tratados e convençóes basilares da sociedade internacional, bem como às normas de jus cogens. Faz-se imprescindível, pois, o cumprimento do Direito Internacional, sobretudo quando respeitá-lo significa um fundado meio de exercer a diplomacia e permitir o atendimento das necessidades da sociedade internacional dos Estados e a proteção dos indivíduos.

Os embates aqui analisados constatam que crimes contra a humanidade foram cometidos durante os governos de Nicolás Maduro e que, portanto, a denúncia feita ao Tribunal Penal Internacional deve ser levada a cabo com acusaçóes sustentadas pela violação do art. $7^{\circ}, \$ 1^{\circ}, e, f, g$, do Estatuto de Roma de 1998 (BRASIL, 2002). No que tange a acusaçáa, nada obsta que novas linhas do parágrafo primeiro do art. $7^{\circ}$ sejam invocadas, desde que comprovados, durante as investigaçóes do tribunal, outros atos que se adequem ao rol do artigo.

10 "Norma imperativa [...] as quais devem ser observadas e cumpridas pela comunidade internacional dos Estados, independentemente da ratificação ou não de instrumentos que tenham validado esse conteúdo" (CIDH, 2017). Prevista na Convenção de Viena Sobre Direitos dos Tratados (BRASIL, 2009) como a Norma Peremptória Geral do Direito Internacional, aceita e reconhecida pela coletividade dos Estados, norma da qual nenhuma derrogaçáo é permitida, salvo por norma ulterior de mesma magnitude, e que leva a nulidade de qualquer tratado que a conflite. 
Entretanto, dada a dificuldade de se precisar todos os crimes cometidos, é provável que a lista destes não seja exaustiva, como praxe do TPI para casos como esse.

A pesquisa atribui inicialmente a Maduro as imputaçôes trazidas na figura do Superior Hierárquico, hipótese que possibilita a responsabilização pelos crimes cometidos pela Guarda Nacional como agentes subordinados ao controle do presidente, não se excluindo a possibilidade de que Maduro tenha agido como mandante de tais crimes.

Tendo em vista o princípio da complementaridade, a jurisdição do Tribunal Penal Internacional não substitui, a priori, a jurisdição nacional, mas incide de maneira subsidiária e complementar, podendo ser aplicada quando as instituiçóes nacionais se mostrarem ineficazes ou omissas na proteção de direitos humanos. Sendo assim, no atual contexto, sem instituiçóes com força nacional e interesse para julgar Maduro, caberia ao TPI a responsabilização do presidente venezuelano.

\section{Referências}

BAPTISTA, A. Bases cuantitativas de la economia venezolana, 1830-1989. Caracas: Fundación Polar, 1991. Disponível em: http://bibliofep.fundacionempresaspolar. org/media/1378171/09-baseseconomia_libro.pdf. Acesso em: 2 jun. 2019.

BARROS, P. S. Chávez e petróleo: uma análise da nova política econômica venezuelana. Cadernos PROLAM/USP, Sáo Paulo, ano 5, v. 2, 2006, p. 209-237. Disponível: em: <http://www.revistas.usp.br/prolam/article/view/81813/85117. Acesso em: 1 jun. 2019.

BRASIL. Presidência da República. Casa Civil. Subchefia para Assuntos Jurídicos. Decreto n. 592, de 6 de julho de 1992. Atos Internacionais. Pacto Internacional sobre Direitos Civis e Políticos. Promulgação. Disponível em: http://www.planalto.gov. br/ccivil_03/decreto/1990-1994/d0592.htm. Acesso em: 3 mar. 2020.

BRASIL. Presidência da República. Casa Civil. Subchefia para Assuntos Jurídicos. Decreto n. 4.388, de 25 de setembro de 2002. Promulga o Estatuto de Roma do Tribunal Penal Internacional. Disponível em: http://www.planalto.gov.br/ ccivil_03/decreto/2002/D4388.htm. Acesso em: 3 mar. 2020.

BRASIL. Presidência da República. Casa Civil. Subchefia para Assuntos Jurídicos. Decreto n. 7.030, de 14 de dezembro de 2009. Promulga a Convenção de Viena sobre o Direito dos Tratados, concluída em 23 de maio de 1969, com reserva aos Artigos 25 e 66. Disponível em: http://www.planalto.gov.br/ccivil_03/_Ato20072010/2009/Decreto/D7030.htm. Acesso em: 3 mar. 2020. 
CASSESSE, A. International Criminal Law. New York: Oxford University Press, 2003.

CASSESE, A. Lineamenti di diritto Internazionale penale. I. Diritto sostanziale. Bologna: Mulino, 2005.

CEPAL - COMISIÓN ECONÓMICA PARA AMÉRICA LATINA Y EL CARIBE. Balance preliminar de las economias de América Latina y el Caribe. Santiago: CEPAL, 2019. Disponível em: https://repositorio.cepal.org/bitstream/ handle/11362/45000/61/BPE2019_Venezuela_es.pdf. Acesso em: 9 jan. 2020.

CIA - CENTRAL INTELLIGENCE AGENCY. The World Factory Book: Venezuela. 8 jan. 2020. Disponível em: https://www.cia.gov/library/publications/ the-world-factbook/geos/ve.html. Acesso em: 9 jan. 2020.

CIDH - COMISSÃO INTERAMERICANA DE DIREITOS HUMANOS. Situación de derechos humanos en Venezuela. Caracas: CIDH, 2017. Disponível em: http://www.oas.org/es/cidh/informes/pdfs/Venezuela2018-es.pdf. Acesso em: 21 jun. 2019.

CORTE INTERAMERICANA DE DIREITOS HUMANOS. Caso Herzog e outros vs. Brasil: sentença de 15 de março de 2018 (exceçóes preliminares, mérito, reparaçôes e custas). 2018. Disponível em: http://www.corteidh.or.cr/docs/casos/ articulos/seriec_353_por.pdf. Acesso em: 21 jun. 2019.

FERNANDES, D. A. O Tribunal Penal Internacional: a concretização de um sonho. Direito \& Paz, Lorena, ano XV, n. 29, p. 302-334, 2013. Disponível em: http://www.mpsp.mp.br/portal/page/portal/documentacao_e_ divulgacao/doc_biblioteca/bibli_servicos_produtos/bibli_boletim/bibli_ bol_2006/2C5E04E70E878823E050A8C0DD016BD2. Acesso em 9 ago. 2019.

GIORDANI, J. Proyectos estratégicos para una nueva etapa. Revista Cuestión, Caracas, dic. 2005.

GOMEZ, L. F. O que se entende pelo princípio da competência sobre a competência? JusBrasil, 2011. Disponível em: https://lfg.jusbrasil.com.br/ noticias/2532337/o-que-se-entende-pelo-principio-da-competencia-sobre-acompetencia. Acesso em: 21 jun. 2019.

GONÇALVES, J. B. Tribunal de Nuremberg 1945-1946: a gênese de uma nova ordem no direito internacional. Rio de Janeiro: Renovar, 2001.

HITNER, V. Uma análise do malogro de desenvolvimento latino-americano dos anos 1990: os limites internos da Venezuela. Monografia (Pós-Graduação) - Faculdade 
de Direito, Universidade de São Paulo, São Paulo, 2011. Disponível em: https:// teses.usp.br/teses/disponiveis/84/84131/tde-18122012-103652/pt-br.php. Acesso em: 2 jun. 2019.

HITNER, V. O esgotamento do modelo puntofijista e a ascensão de Chávez. Revista Espaço Acadêmico, Maringá, ano XII, n. 137, out. 2012. Disponível em: http:// periodicos.uem.br/ojs/index.php/EspacoAcademico/article/view/18704/9877. Acesso em: 6 jun. 2019.

ICC - INTERNATIONAL CRIMINAL COURT. ICC, 2018. Disponível em: https://www.icc-cpi.int/. Acesso em: 10 jun. 2019.

ICC - INTERNATIONAL CRIMINAL COURT. Statement of the Prosecutor of the International Criminal Court, Fatou Bensouda, on the referral by a group of six States Parties regarding the situation in Venezuela. 26 set. 2018. Disponível em: https://www.icc-cpi.int/Pages/item.aspx?name=180927-otp-stat-venezuela. Acesso em: Acesso em: 8 jan. 2020.

LOPES, A. L. O governo de Chávez e o ensaio de superação do rentismo venezuelano: do nacionalismo bolivariano ao socialismo do século XXI. Monografia (PósGraduação) - Faculdade de Ciências e Letras de Araraquara, Universidade Estadual Paulista, Araraquara, 2011.

MPD - MINISTERIO DE PLANIFICACIÓN Y DESARROLLO. 2000-2003: 3 años de la VRepública - Venezuela construye su camino. Caracas, 2004. Disponível em: http://www.mpd.gov.ve. Acesso em: 2 jun. 2019.

OHCHR - OFFICE OF THE UNITED NATIONS HIGH COMMISSIONER FOR HUMAN RIGHTS. Report of the United Nations High Commissioner for Human Rights on the situation of Human rights in the Bolivarian Republic of Venezuela. 05 jul. 2019. Disponível em: https://www.ohchr.org/EN/NewsEvents/ Pages/DisplayNews.aspx?NewsID=24788\&LangID=E. Acesso em: 13 jan. 2020

ORGANIZAÇÃO DOS ESTADOS AMERICANOS. Convenção Interamericana para Prevenir, Punir e Erradicar a Violência Contra a Mulher. Belém do Pará, Brasil, 9 jun. 1984. Disponível em: http://www.cidh.org/Basicos/Portugues/m.Belem. do.Para.htm. Acesso em: 21 jun. 2019.

ORGANIZAÇÃO DOS ESTADOS AMERICANOS. Convenção Interamericana para Prevenir e Punir a Tortura. 12 set. 1985. Disponível em: http://www.oas.org/ juridico/portuguese/treaties/a-51.htm. Acesso em: 21 jun. 2019.

ORGANIZAÇÃO DOS ESTADOS AMERICANOS. Report Of The General 
Secretariat Of The Organization Of American States And The Panel Of Independent International Experts On The Possible Commission Of Crimes Against Humanity In Venezuela. Washington, D.C, maio. 2018. Disponível em: https://reliefweb.int/ sites/reliefweb.int/files/resources/Informe-Panel-Independiente-Venezuela-EN. pdf. Acesso em: 9 jan. 2020.

SANTANA, G. S. Leyes, Decretos Normativos, Reglamentos y Resoluciones de efectos generales dictados durante el Primer Semestre de 2017. Revista de Derecho Público de Venezuela, Caracas, n. 513, p. 219-243, jan. 2018. Disponível em: https://2019.vlex.com/\#WW/vid/787330805. Acesso em: 9 jan. 2020.

SILVA, A. P. Direito internacional penal (direito penal internacional?): breve ensaio sobre a relevância e transnacionalidade da disciplina. Rev. Fac. Direito UFMG, Belo Horizonte, n. 62, p. 53-83, jan./jun. 2013. Disponível em: https://www. direito.ufmg.br/revista/index.php/revista/article/view/P.0304-2340.2013v62p56. Acesso em: 9 ago. 2019.

VENEZUELA. Constituição da República Bolivariana da Venezuela, 1999. Disponível em: https://www.oas.org/dil/esp/Constitucion_Venezuela.pdf. Acesso em: 15 jun. 2019.

VENEZUELA: o legado autoritário de Chávez. Human Rights Watch, 5 mar. 2013. Disponível em: https://www.hrw.org/pt/news/2013/03/05/249002. Acesso em: 20 jun. 2019.

VILLA, R. D. Venezuela: mudanças políticas na era Chávez. Estudos Avançados, São Paulo, v. 19, n. 55, p. 153-172, 2005. 